\title{
Traumatic injuries of peripheral nerves: a review with emphasis on surgical indication
} Lesões traumáticas de nervos periféricos: uma revisão com ênfase na indicação cirúrgica Roberto Sergio Martins ${ }^{1,2}$, Dhiego Bastos ${ }^{3}$, Mario Gilberto Siqueira', Carlos Otto Heise?, Manoel Jacobsen Teixeira ${ }^{1}$

\section{ABSTRACT}

Traumatic peripheral nerve injury is a dramatic condition present in many of the injuries to the upper and lower extremities. An understanding of its physiopathology and selection of a suitable time for surgery are necessary for proper treatment of this challenging disorder. This article reviews the physiopathology of traumatic peripheral nerve injury, considers the most used classification, and discusses the main aspects of surgical timing and treatment of such a condition.

Keywords: peripheral nerve, peripheral nerve surgery, peripheral nerve injury, nerve.

\section{RESUMO}

Traumatismos dos nervos periféricos resultam em lesões incapacitantes e estão presentes em muitas das lesões dos membros. A compreensão da fisiopatologia dessas lesões e a seleção do momento operatório mais adequado são imprescindíveis para que o tratamento seja adequado. Neste artigo revisamos a fisiopatologia das lesões traumáticas dos nervos periféricos, apresentamos a classificação mais utilizada dessas lesões e discutimos os principais aspectos relacionados ao momento da cirurgia e às formas de reparo cirúrgico.

Palavras-chave: nervo periférico, cirurgia de nervo periférico, traumatismo de nervo periférico, enxerto de nervo, reparo do nervo.

Acute peripheral nerve injuries are one of the complications of trauma affecting the extremities, and is present in $3-10 \%$ of patients, depending on the mechanism of trauma ${ }^{1-3}$. These traumatic injuries are a significant cause of physical disability that affects mainly young adults of working age. Although some nerve injuries recover spontaneously, in some cases surgery is the only therapeutic option for the improvement of neurological deficits or control of neuropathic pain. Indications for surgery in patients with peripheral nerve injury depends on several variables including mechanism of injury, interval between injury and treatment, lesion severity, findings of the clinical examination, and intensity of neuropathic pain ${ }^{4}$.

In this article we review the classification, mechanisms and evaluation of peripheral nerve injuries, with emphasis on indications for surgical treatment.

\section{CLASSIFICATION OF PERIPHERAL NERVE INJURY}

A key issue in defining surgical treatment for patients with peripheral nerve injury is to determine whether the injury results in an open or closed lesion ${ }^{5}$. The severity of the injury is variable and can be classified according to Seddon's classification in three types: neuropraxia, axonotmesis, and neurotmesis ${ }^{4}$ (Figure 1).
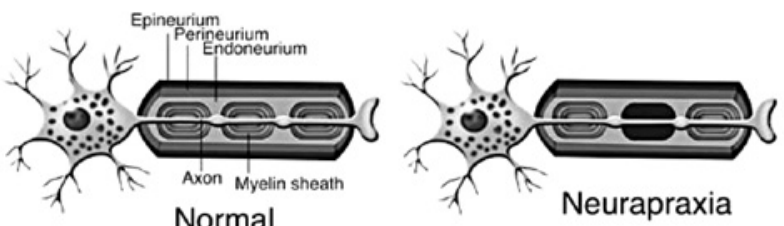

Normal

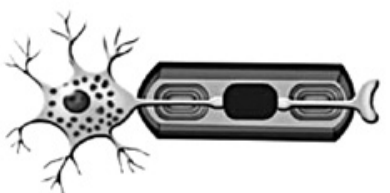

Axonotmesis

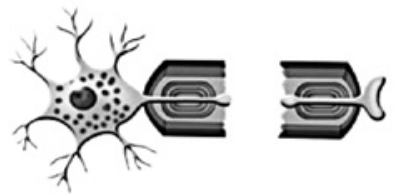

Neurotmesis

Figure 1. Schematic drawing of a normal nerve fiber and the three grades of nerve injury according to Seddon's classification.

\footnotetext{
${ }^{1}$ Peripheral Nerve Surgery Unit, Department of Neurosurgery, University of São Paulo School of Medicine, São Paulo SP, Brazil;

${ }^{2}$ Hospital do Servidor Público do Estado de São Paulo, São Paulo SP, Brazil;

3Universidade Estadual de Campinas, Campinas SP, Brazil.

Correspondence: Roberto S. Martins; Rua Oscar Freire 2250 / cj. 18 térreo; 05409011 São Paulo SP - Brasil; E-mail: robar@ig.com.br

Conflict of interest: There is no conflict of interest to declare.

Received 16 May 2013; Received in final form 20 May 2013; Accepted 27 May 2013.
} 
Neurapraxia represents the mildest type of nerve injury and is defined by a temporary blockage of nervous conduction caused by a segmental demyelinization ${ }^{5}$. The large fibers are more selectively and severely affected than the small fibers, leading to motor paralysis, and some proprioceptive and tactile sensitivity loss, but with maintenance of thermal and pain sensitivity in most cases. The prognosis is excellent since there is no distal axonal degeneration; the blockage resolves through remyelinization and the nerve function is recovered in a matter of days or weeks 4 .

Axonotmesis occurs when the injury is sufficient to determine the loss of axonal continuity, but most of nerve connective tissue framework is preserved, including the tubular endoneural support that surrounds each axon ${ }^{5}$. Despite the damage being more extensive in axonotmesis than in neurapraxia, spontaneous regeneration is still possible, although longer, taking up weeks to months after the injury. In axonotmesis, as well as in neurotmesis, a sequence of pathological events known as wallerian degeneration occurs in the nerve segment distal to the injury. This process includes fragmentation and degeneration of the axon distal to the lesion and phagocytosis of the myelin sheath by Schwann cells and macrophages ${ }^{6}$. In a phase of the process, the distal endoneural tubes are filled by Schwann cells forming longitudinal lines inside the tubes known as Büngner's bands? The recovery depends on the axonal sprout from the proximal stump that must cross the lesion site and reach the correspondent endoneural tubes in the distal stump in order to reinnervate the target organ. Once the Büngner's band is reached, the axon grows $1-3 \mathrm{~mm}$ a day ${ }^{8,9}$. Thereby, reinnervation of the target organ can take several months depending on its distance from the lesion. The re-establishment of the neuromuscular junctions depends on the interaction between regenerating axons and basal membranes of the myofibrils. Soon after nerve injury, degeneration of myofibers occurs and 1824 months after the injury muscle fibers are replaced by fat and fibrous connective tissue, which makes the muscle progressively refractory to reinnervation ${ }^{4}$. Therefore, the sooner the axons reach the muscle fibers, the more effective reinnervation can be expected and that is the reason why surgery for nerve injury, when indicated, must be performed as soon as possible ${ }^{10}$.

In neurotmesis, besides the loss of axonal continuity and of the internal nerve connective tissue framework, a rupture occurs in the epineurium with macroscopic loss of nerve continuity or interposition of scar tissue between the interrupted fibers, which prevents spontaneous regeneration and requires surgical treatment $t^{4}$. The correct identification of these lesions is the main objective of the surgeon dealing with such event.

\section{OPEN VERSUS CLOSED INJURIES}

Nerve injuries can be classified as closed and open depending on whether the cutaneous integrity has been disrupted or not. Closed injuries are more frequently associated with nerve injuries in continuity, characterized by absence of nerve rupture and by occurrence of neuropraxis and axonotmesis as the predominant mechanisms of injury ${ }^{11}$. Therefore, spontaneous recovery is possible and surgery is indicated only after 3 months if no recovery is identified. This period is arbitrated based on axonal growth rate (1-3 $\mathrm{mm} /$ day) and improvement identified on clinical or electromyographic evaluation. Classical examples of closed injuries are those resulting from stretching after brachial plexus injuries secondary to motorcycle falls and peroneal nerve injuries associated with knee dislocation and concomitant ligament lesion ${ }^{12}$.

Conversely, the occurrence of an open injury related to a nerve course has been more frequently related to neurotmetic injuries and must be treated with early surgery ${ }^{12}$. Examples of these injuries include those provoked by knives, propellers, piece of glass, and scalpel iatrogenic lesions. Within this context, it is important to keep in mind that the distal portion of the nerve undergoes wallerian degeneration that occurs up 2 to 3 weeks after the injury ${ }^{8}$. So, electrophysiological assessment is not indicated in these cases before 3-4 weeks, since false results may compromise the evaluation.

\section{SHARP VERSUS BLUNT INJURIES}

The aspect of the nerve stumps identified during surgery is another important factor to be considered for the definitive treatment ${ }^{11,13}$. Two situations can be distinguished: identification of a sharp stump with homogeneous aspect and no significant inflammation; or finding a blunt or rugged stump, associated with significant inflammatory process, heterogeneous aspect, and contusion (Figure 2). Sharp instruments like knives or scalpels have been identified as a frequent causative factors resulting in sharp stumps. In these cases, the repair should be done promptly, if possible within

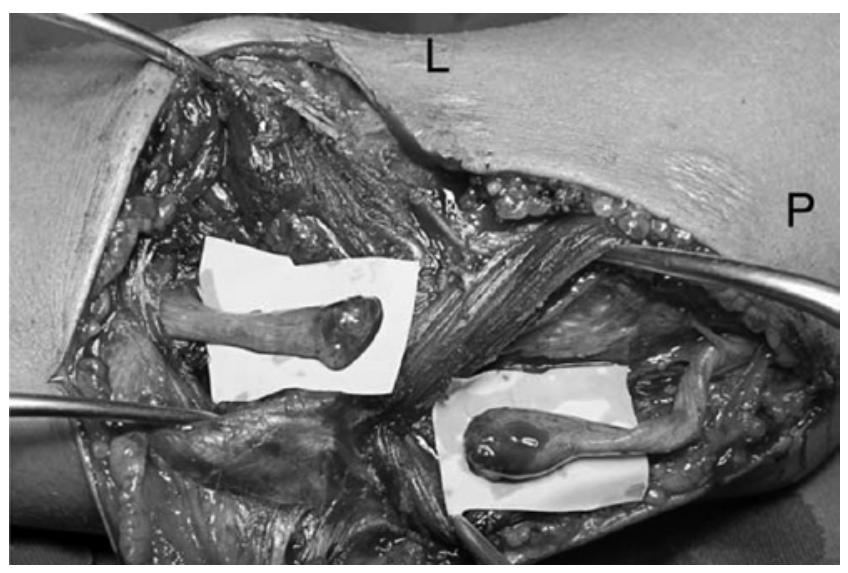

Figure 2. Intrao perative view of ulnar nerve approach in the right forearm. This 22-year-old patient suffered a stab wound 4 months before his presentation at our center. A complete palsy of the ulnar nerve was identified at physical examination and a neurotmesis was demonstrated during surgical procedure. Note the large neuroma of the proximal stump. L: lateral side; P: proximal. 
the first 3 days after the injury. Usually a direct coaptation of the nerve ends can be performed with a termino-terminal tension-free suture ${ }^{12}$.

Technical conditions in performing surgery is another important issue that must be taken into consideration when deciding on an early repair ${ }^{14}$, as an adequate surgical technique has been accepted as one of the factors that influence the final result after a nerve surgery ${ }^{15}$. This implies the use of microscope magnification, 9.0- or 10.0-caliber sutures, and a careful manipulation of nerve structures using microsurgical instrumental $^{16}$. If there are no such conditions for surgery, the epineurium of each nerve stump should be sutured to some adjacent structure, such as a tendon or fascia, in order to avoid excessive retraction of the stumps and to facilitate its identification in a second surgical procedure ${ }^{14}$. Any attempt to suture the nerve beyond these conditions will result in unnecessary damage to nerve tissue, increase in local fibrosis, and worse functional results at long-term follow-up.

When blunt stumps are identified during surgery (Figure 2 ), the repair should not be performed immediately because the inflammatory process that takes place extends for up to 3 weeks after the injury ${ }^{11}$. If repair is performed within this period there is a risk to connect nerve stumps still involved in an ongoing inflammatory process that results in fibrosis and prevents progression of the regenerated axons. When blunt nerve stumps are identified, the surgeon should interrupt the procedure and perform the definitive repair 3 weeks after the injury ${ }^{11}$. During the definitive repair the inflammatory tissue and fibrosis must be resected by trimming the nerve ends with a scalpel blade until viable fascicles have being exposed ${ }^{17}$.

\section{THE "RULE OF THREE"}

In summary, surgical timing in a traumatic peripheral nerve injury is defined by the "rule of three": immediate surgery within 3 days for clean and sharp injuries; early surgery within 3 weeks for blunt/contusion injuries; and delayed surgery, performed 3 months after injury, for closed injuries.

\section{SPECIAL SETTINGS}

Nerve injuries due to gunshot wounds have been considered closed injuries since there is no tissue exposure. Most lesions are caused by indirect heat and by the shock wave from the bullet. Usually the projectile does not transect the nerve so continuity is preserved and there is potential for at least partial spontaneous recovery. Therefore, surgery for patients with nerve injuries due to gunshot wounds should be performed 3-4 months after the injury ${ }^{18}$.

Another condition that does not follow the "rule of three" occurs when an injured nerve is located in an area where non-related surgery had been performed previously. An emergency vascular intervention nearby the nerve is an example of such a condition ${ }^{19}$. Another example is an orthopedic exploration of an open humerus fracture exposing the adjacent radial nerve ${ }^{20}$. In both situations the lesion originally classified as closed may result in nerve transection, and the early exploration allows performing nerve surgery before the usual 3-month period of observation.

\section{SURGICAL CONSIDERATIONS}

Classically surgery for treatment of peripheral nerve injuries should be considered in patients demonstrating complete palsy after the traumatism. Persistent neuropathic pain besides medical treatment is another indication, and, in these cases, neurolysis, which consists in the removal of a fibrotic hypertrophic epineurium and adherent adjacent tissue to the nerve, should result in partial or total pain relief ${ }^{14}$.

Adequate surgical management of peripheral nerve injuries requires that the surgeon, beyond knowing precisely the anatomical details of the region to be assessed, also be familiarized with microsurgical techniques and dispose of the necessary equipment to perform the surgery ${ }^{14}$. The basic procedure in peripheral nerve surgery is the re-establishment of nerve continuity, which can be obtained by direct coaptation between the two stumps of the ruptured nerve or by interposition of nerve grafts ${ }^{21}$. The best results are achieved with end-to-end nerve repair without tension, as the regenerating axons need to cross just one site of coaptation. In contrast, when using nerve graft, the regenerating axons need to cross two sites of repair, which may have a distinct inflammatory process, resulting in higher axonal loss ${ }^{13}$. However, in many cases approximation of the nerve stumps results in tension on the suture line. Tension at the site of repair results in ischemia, connective tissue proliferation, and scar formation that impair or prevent the regenerating axons to progress ${ }^{21}$. In these cases the reconstruction of nerve continuity is accomplished by the interposition of autologous nerve grafts, usually from the sural nerve.

Intraoperative eletrophysiologic evaluation has been accepted as an important tool in the management of lesions in continuity (Figure 3A) ${ }^{22}$. In this type of lesion, also named neuroma in continuity, it is difficult to define the extent of internal nerve damage by macroscopic inspection only. In some cases, the presence of healthy axons inside the neuroma allows spontaneous regenerations, but in others the scar tissue represents an obstacle to the regenerating axons. In this last situation, the scar tissue needs to be resected and substituted by normal nervous tissue usually by interposition of autologous nerve graft. These specifics cases should be evaluated through nerve action potential (NAP) measurement (Figure 3B). This evaluation is performed using a portable electromyography device and two electrodes. With a hook form, the stimulating and the recording electrodes are positioned under and around the nerve, proximal and distal to the neuroma, respectively, elevating and isolating the nerve. A supramaximal stimulus is then applied to generate an action potential. When a recordable NAP (axonotmetic injury) 

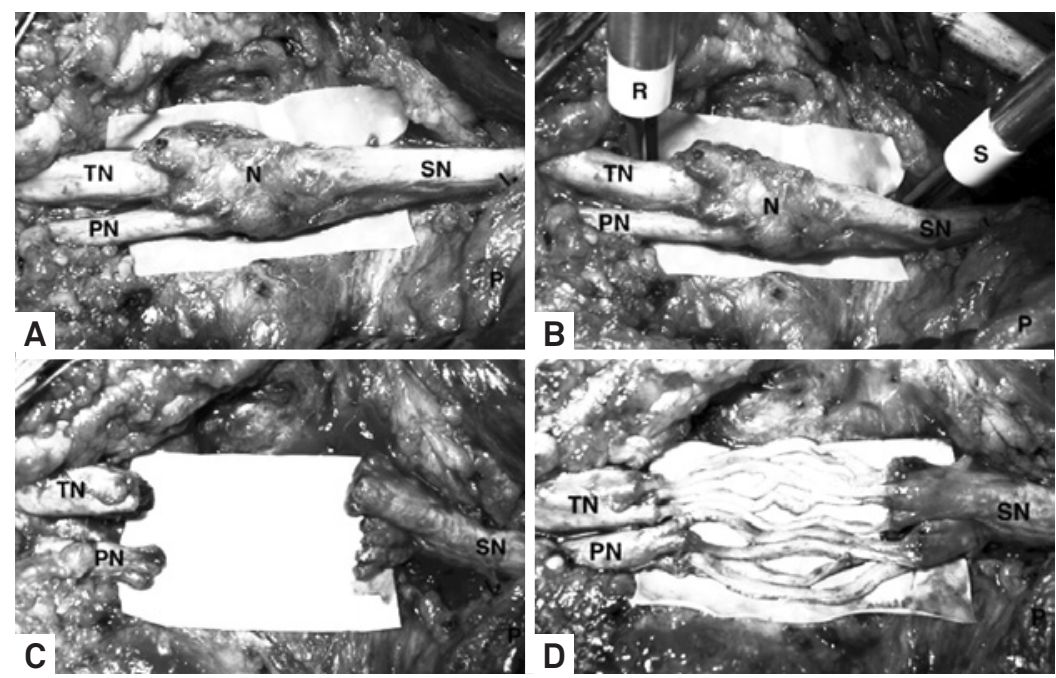

Figure 3. Intraoperative photograph showing a sciatic nerve injury at the middle third of the thigh due to a gunshot wound. Since there was no recovery of a complete sciatic nerve palsy the patient was operated 3 months after injury. (A) Initial exposure showing a neuroma $(\mathrm{N})$ in continuity of the sciatic nerve (SN) just before its division. (B) An intraoperative nerve action potential evaluation was performed in order to define if the lesion should be resected. No recordable response was obtained so the neuroma was resected. (C) Surgical view after neuroma resection. (D) Both sural nerves were used to re-establish nerve continuity with nine nerve grafts interposed between proximal and distal stumps. P: proximal; PN: peroneal nerve; R: recording electrode; S: stimulation electrode; TN: tibial nerve.

is identified there are regenerating axons passing through the neuroma, regeneration will likely occur, and an external neurolysis is the only surgical procedure to be done. When there are no regenerating axons crossing the lesion no NAP will be recorded and resection of the neuroma followed by nerve reconstruction, usually with grafts, is performed (Figure 3C, D).

In conclusion, the social cost of traumatic peripheral nerve injuries is significant since it has a higher incidence on young, previously healthy, and economically active people. A prompt and adequate handle of these lesions can result in the recovery, at least partially, of the lost function. Therefore it is fundamental to understand the mechanisms and peculiarities of these lesions in order to define an acceptable time for surgical intervention. Timely nerve reconstruction performed with suitable microsurgical technique improves the functional recovery of this disabling condition.

\section{References}

1. Hudson AR, Hunter D. Timing of peripheral nerve repair: important local and neuropathological factors. Clin Neurosurg 1977;24:391-405.

2. Deitch EA, Grimes WR. Experience with 112 shotgun wounds of the extremities. J Trauma 1984;24:600-603.

3. Noble J, Munro CA, Prasad VS, Midha R. Analysis of upper and lower extremity peripheral nerve injuries in a population of patients with multiple injuries. J Trauma 1998;45:116-122.

4. Campbell WW. Evaluation and management of peripheral nerve injury. Clin Neurophysiol 2008;119:1951-1965.

5. Grant GA, Goodkin R, Kliot M. Evaluation and surgical management of peripheral nerve problems. Neurosurgery 1999;44:825-840.

6. Schmid DB, Salyapongse N. Nerve injury and repair. Curr Orthop Pract 2008;19:475-480.

7. Torigoe K, Tanaka H, Takahashi A, Awaya A, Hashimoto K. Basic behavior of migratory Schwann cells in peripheral nerve regeneration. Exp Neurol 1996;137:301-308.

8. Hall S. Nerve repair: a neurobiologist's view. J Hand Surg $(\mathrm{Br})$ 2001;26:129-136.

9. Gordon T, Chan KM, Sulaiman OAR, Udina E, Amirjani N, Brushart TM. Accelerating axon growth to overcome limitations in functional recovery after peripheral nerve injury. Neurosurgery 2009;65:132-44.

10. Robinson LR. Traumatic injury to peripheral nerve. Muscle Nerve 2000;23:863-873.

11. Spinner RJ, Kline DG. Surgery for peripheral nerve and brachial plexus injuries or other nerve lesions. Muscle Nerve 2000;23:680-695.
12. Weber RV, Mackinnon SE. Bridging the neural gap. Clin Plast Surg 2005;32:605-616.

13. Isaacs J. Treatment of acute peripheral nerve injuries: current concepts. J Hand Surg (Am) 2010;35:491-497.

14. Harris ME, Tindall SC. Techniques of peripheral nerve repair. Neurosurg Clin North Am 1991;2:93-104.

15. Rowshan K, Jones NF, Gupta R. Current surgical techniques of peripheral nerve repair. Operat Tech Ortop 2004;14:63-170.

16. Sunderland $\mathrm{S}$. The anatomic foundation of peripheral nerve repair techniques. Orthop Clin North Am 1981;12:245-266.

17. Dahlin LB. Nerve injuries. Curr Orthop 2008;22:9-16.

18. Katzman BM, Bozentka DJ. Peripheral nerve injuries secondary to missiles. Hand Clin 1999:15:233-244.

19. Manord JD, Garrard CL, Kline DG, Sternbergh WC 3rd, Money SR. Management of severe proximal vascular and neural injury of the upper extremity. J Vasc Surg 1998;27:43-47.

20. Thomsen NOB, Dahlin LB. Injury to the radial nerve caused by fracture of the humeral shaft: timing and neurobiological aspects related to treatment and diagnosis. Scand J Plast Reconstr Surg Hand Surg 2007;41:153-157.

21. Dvali L, Mckinnon S. The role of microsurgery in nerve repair and nerve grafting. Hand Clin 2007;21:73-81.

22. Sulaiman WAR. Kline DG. Nerve surgery: a review and insights about its future. Clin Neurosurg 2006;53:38-47. 